\title{
Thiazolo-Pyrimidline Analogues: Synthesis, Characterization and Docking Studies Guided Antimicrobial Activities
}

\author{
Umesha K. Bhadraiah 1(D), Srikantamurthy Ningaiah 2 (D), Vrushabendra Basavanna ${ }^{2}$ (D), Dileep C \\ Shanthakumar $^{3(D)}$, Manasa Chandramouli ${ }^{2}(\mathrm{D})$, Chandra ${ }^{4}(\mathrm{D})$, ThejeshKumar M. Puttaswamy 5 (D), \\ Shridevi Doddamani 6,*(i)

\footnotetext{
Department of Chemistry, Yuvaraja's College, University of Mysore, Mysore-570005, Karnataka, India Department of Chemistry, Vidyavardhaka College of Engineering, Mysore-570002, Karnataka, India Department of Physics, Vidyavardhaka College of Engineering, Mysore-570002, Karnataka, India Department of Physics, National Institute of Engineering, Mysuru-570008, Karnataka, India Department of Studies in Botany, University of Mysore, Manasagangotri, Mysore-570006, Karnataka, India
} \\ 6 Chemical Sciences and Technology Division, CSIR-NIIST, Thiruvananthapuram-695 019, Kerala, India \\ * Correspondence: shridevi20@gmail.com;
}

Received: 10.08.2020; Revised: 7.09.2020; Accepted: 9.09.2020; Published: 13.09.2020

\begin{abstract}
In the current study, bicyclic 1-(7-methyl-3,5-diphenyl-5H-thiazolo(3,2- $\alpha$ )pyrimidine-6yl)ethanone (4a-l) derivatives have been designed and conveniently synthesized by one-pot threecomponent method via cyclocondensation of substituted 4-phenylthiazole-2-amine (1a-c), acetylacetone (2) and various aromatic aldehydes (3a-d) in the presence of $p$-toluene sulfonic acid (PTSA) under acetonitrile solvent medium. The synthesized compounds (4a-1) have been characterized by spectral analysis and subjected to docking study against protein DNA gyrase (PDB Code: 1KZN), and also, the compounds were screened for their in vitro antimicrobial activities. The bioassay of the synthesized compounds envisioned that the compound $4 \mathrm{k}$ emerged as a broad-spectrum antibacterial agent, and 41 emerged as a good antifungal agent compared to standard drug.
\end{abstract}

Keywords: thiazolo[3,2- $\alpha]$ pyrimidine; one-pot three-component reaction; docking studies; antimicrobial activity.

(C) 2020 by the authors. This article is an open-access article distributed under the terms and conditions of the Creative Commons Attribution (CC BY) license (https://creativecommons.org/licenses/by/4.0/).

\section{Introduction}

The fusion of two rings thiazole and pyrimidine containing bridgehead nitrogen atom [1-2] are attracting the attention of many medicinal chemists throughout the world to explore the framework for its potential [3]. Ritanserin and setoperone are the most common example of a biologically active compound containing thiazolopyrimidines system [4]. Thiazolo[3,2$\alpha$ ]pyrimidines, which is being used in various fields of therapeutic applications [5] such as antimicrobial [6-8], antiviral [9], cytotoxicity [10], insecticides [11], analgesic [12], antioxidant [13], anti-inflammatory [14] and calcium channel blocker activities [15-16]. Additionally, it was described that such a ring system could inhibit the enzyme 3'5'-cyclic AMP phosphodiesterase to have a theophylline-like activity and to be active against virulent Lewis lung tumors in mice [17]. Thiazolo[3,2- $\alpha$ ]pyrimidine derivatives to generate enzyme inhibitors as novel therapeutical entities for severe neurodegenerative diseases and other medicinal applications [18]. 
The synthesis of dihydropyrimidines is a well-known three-component one-pot reaction of a substituted aldehyde, 1,3-dicarbonyl compound, and thiourea to give Biginelli compounds [19]. The Hantzsch-type condensation of dihydropyrimidines with a substituted phenacyl chlorides led to the 3-substituted-5H-thiazolo[3,2- $\alpha$ ]pyrimidine derivatives [20-21]. Hussein $e t$ $a l$. have been synthesized ethyl 6-methyl-4-(substituted)phenyl-2-(substituted)-phenacylthio1,4-dihydropyrimidine-5-carboxylate hydrobromide series and screened for their antibacterial and antifungal activities [22].

Renata et al. [23] described the preparation of 2-iodomethyl/2-bromomethyl-2,3dihydrothiazolo[3,2- $\alpha]$ pyrimidine-5-one derivatives containing alkyl groups at C-6 and/or C-7 via the reaction of 3-allyl-2-thiouracils with iodine chloride/bromide in methanol and Amit $\mathrm{K}$ Keshari et al. [24] have been successfully utilized $p$-toluene sulfonic acid (PTSA) catalyzed domine Knoevenagel/Michael/intramolecular cyclization for the synthesis of novel $5 \mathrm{H}$ benzo[h]thiazolo[2,3-b]quinazoline and indeno[1,2-d]thiazolo[3,2- $\alpha$ ]pyrimidine analogs bearing bridgehead nitrogen atom. The newly synthesized compounds were tested for molecular modeling and in vitro antitumor activity against hepatocellular carcinoma.

Recently, Asieh Khalilpour et al. [25] synthesized and investigated in vitro cytotoxicity and antioxidant activity of 2,3-dihydro-5H-[1,3]thiazolo[3,2- $\alpha]$ pyrimidine-2,3,6tricarboxylates derivatives. The chlorine substituted compound displayed the highest cytotoxic effect in comparison with standard drug doxorubicin and effective antioxidant. Janardhan Banothu and co-workers [26] synthesized and screened for their antibacterial, antioxidant, and DNA cleavage activities of the series of thiazolo[3,2-a]pyrimidines in good yield by the reaction of fused 3,4-dihydropyrimidine-2(1H)-thiones with phenacyl bromides/3-(2bromoaceyl)coumarins under conventional heating in acetic acid medium.

This prompted us to develop the process for the synthesis of some bicycle heterocyclic compounds containing 1,3,4-thiadiazine fused with pyrimidine moiety, i.e., 1-(7-methyl-3,5diphenyl-5H-thiazolo[3,2- $\alpha$ ]pyrimidine-6-yl)ethanone (4a-1) derivatives and study their antimicrobial studies.

\section{Materials and Methods}

All chemicals/reagents were procured from Merck/Fluka Chemicals (India). The melting points were measured with micro melting point apparatus and are uncorrected. IR spectra were recorded in $\mathrm{KBr}$ pellets on Shimadzu 8300 spectrometer. The ${ }^{1} \mathrm{H} \mathrm{NMR}\left(\mathrm{CDCl}_{3}\right)$ was recorded on Agilent NMR-vnrms $400 \mathrm{MHz}$ spectrometer; the chemical shifts are expressed in ppm (TMS as internal standard). ${ }^{13} \mathrm{C}$ NMR (DMSO-d6) spectra were obtained on Varian Gemini $100 \mathrm{MHz}$ spectrometer, Mass spectra were obtained on Agilent 6330 ion trap spectrophotometer, and elemental analysis was performed on a Jusco micro-analytical data unit. TLC was achieved on pre-coated silica gel sheets (HF 254, Sd-fine), and visualization of the spots was done in iodine vapor and UV light. Chromatographic separation was carried out on silica gel (60-120) mesh using petroleum ether: acetone (9:1) as eluent.

\subsection{General procedure.}

General procedure for the synthesis of 4-phenylthiazole-2-amine (1a): Solution of acetophenone $(2.40 \mathrm{~g}, 20.00 \mathrm{mmole})$ and thiourea $(1.90 \mathrm{~g}, 25.00 \mathrm{mmole})$ are taken in a roundbottomed flask, $10 \%$ bromine in acetic acid $(25 \mathrm{ml})$ was slowly added to the flask with constant stirring. After the addition of bromine in acetic acid, the reaction mass was refluxed on a water 
bath until most of the solid has gone into a solution and again refluxed the solution for 2-3 hours. The hot reaction mixture was filtered; the filtrate was cooled and alkaline with conc. ammonium hydroxide to separate solid 4-phenylthiazole-2-amine [27]. The obtained product was filtered, washed with alcohol, and dried over $\mathrm{P}_{2} \mathrm{O}_{5}$. It was recrystallized from ethanol to get colorless needles (1a). Yield (84.2\%), m.p. $120-122^{\circ} \mathrm{C}$.

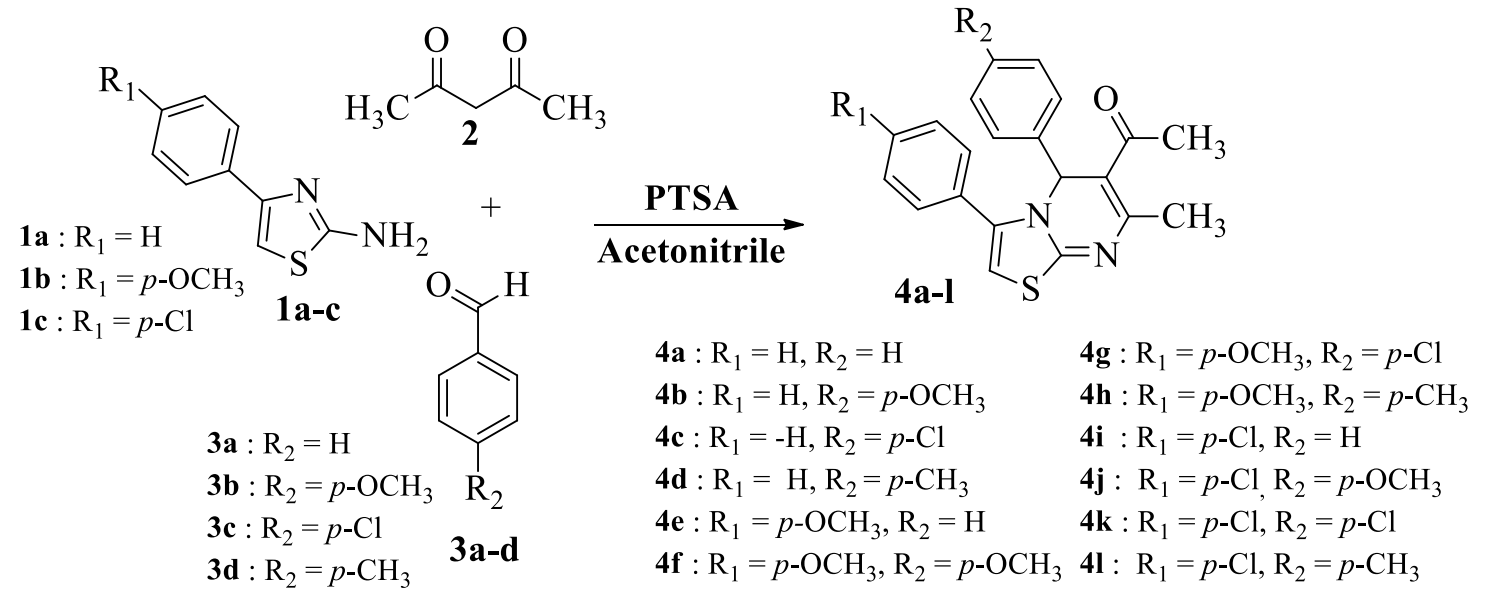

Scheme 1. Synthesis of thiazolo-pyrimidine derivatives.

The typical procedure for the synthesis of 1-(7-methyl-3,5-diphenyl-5H-thiazolo[3,2$\alpha$ ]pyrimidine-6-yl)ethanone (4a): The solution of acetylacetone $(2,2.00 \mathrm{~g}, 20.00 \mathrm{mmol})$ and benzaldehyde $(3 \mathrm{a}, 1.06 \mathrm{~g}, 10.00 \mathrm{mmol})$ in acidic PTSA $(2.50 \mathrm{~g}, 15.00 \mathrm{mmol})$ was refluxed on a water bath in the presence of acetonitrile $(25 \mathrm{ml})$ for about 30 minutes. Meanwhile, the 4phenylthiazole-2-amine (1a, 1.76g, 10.00mmol) was added to the same reaction mixture and again refluxed for about 2-3 hours. After the completion (monitored by TLC), the reaction mixture was cooled to room temperature, extracted with $\mathrm{CHCl}_{3}(3 \times 25 \mathrm{ml})$, washed with water $(2 \times 25 \mathrm{ml})$, and $2 \%$ dilute $\mathrm{HCl}$ solution, finally dried over anhydrous $\mathrm{Na}_{2} \mathrm{SO}_{4}$. The solvent was evaporated to give yellow viscous solid, which was subjected to chromatographic (silica gel 60-120 mesh) using petroleum ether and ethyl acetate (8:2) as eluent to get a pale yellow solid 1-(7-methyl-3,5-diphenyl-5H-thiazolo(3,2- $\alpha$ )pyrimidine-6-yl)ethanone $4 \mathrm{a}$ in $82 \%$ yield (2.83g); m.p. $114-116^{\circ} \mathrm{C}$.

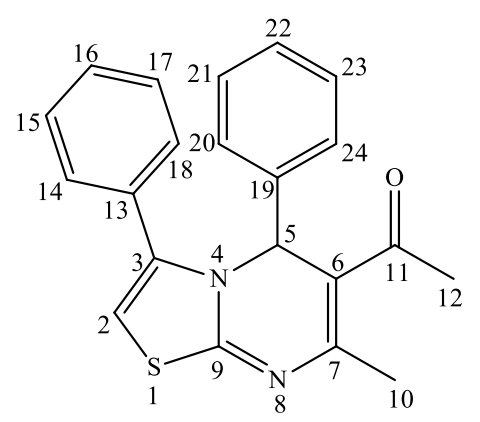

$4 \mathbf{a}$

IR (KBr, cm $\left.{ }^{-1}\right): \gamma 2970(-\mathrm{CH}-), 1678(>\mathrm{C}=\mathrm{O}), 1566(-\mathrm{C}=\mathrm{N}-) \mathrm{cm}^{-1}$; ${ }^{1} \mathrm{H} \mathrm{NMR}\left(\mathrm{CDCl}_{3}\right): \delta 2.26\left(\mathrm{~s}, 3 \mathrm{H},-\mathrm{COCH}_{3}\right), 2.94\left(\mathrm{~s}, 3 \mathrm{H},-\mathrm{CH}_{3}\right)$, $5.22(\mathrm{~s}, 1 \mathrm{H},-\mathrm{CH}-),), 6.96(\mathrm{~s}, 1 \mathrm{H},>\mathrm{C}=\mathrm{CH}-), 7.25-7.75(\mathrm{~m}, 10 \mathrm{H}$, Ar-H; ${ }^{13} \mathrm{C}$ NMR (DMSO- $d 6$ ): $\delta 21.12$ (C-10), 27.21 (C-12), 65.20 (C-5), 108.42 (C-2), 126.24 (C-3), 126.80 (C-22), 127.06 (C-20 and C-24), 128.04 (C-16), 128.21 (C-14 and C-18), 128.66 (C-21 and C-23), 128.82 (C-15 and C-17), 130.80 (C-13), 131.62 (C-6), 143.44 (C-19), 151.83 (C-7), 158.64 (C-9), 196.62 (C-11); MS for $\mathrm{C}_{21} \mathrm{H}_{18} \mathrm{~N}_{2} \mathrm{OS}: 346\left(\mathrm{MH}^{+}, 100 \%\right), 347\left(\mathrm{MH}^{+1}, 23 \%\right), 348\left(\mathrm{MH}^{+2}\right.$, 4.8\%); Elemental Analysis (\%): Calculated: C, 72.80.12; H, 5.24; N, 8.09; Found: C, 72.76; H, 5.26; N, 8.08.

1-(5-(4-methoxyphenyl)-7-methyl-3-phenyl-5H-thiazolo[3,2- $\alpha$ ]pyrimidine-6-yl)ethanone (4b): Obtained from 4-phenylthiazole-2-amine (1a, $1.76 \mathrm{~g}, 10.00 \mathrm{mmol})$, acetylacetone (2, $2.00 \mathrm{~g}, 20.00 \mathrm{mmol})$ 4-methoxybenzaldehyde $(3 \mathrm{~b}, 1.36 \mathrm{~g}, 10.00 \mathrm{mmol})$ and PTSA $(2.50 \mathrm{~g}$, $15.00 \mathrm{mmol})$ as yellow solid, yield $85 \%(3.19 \mathrm{~g})$, m.p. $120-122^{\circ} \mathrm{C}$. 


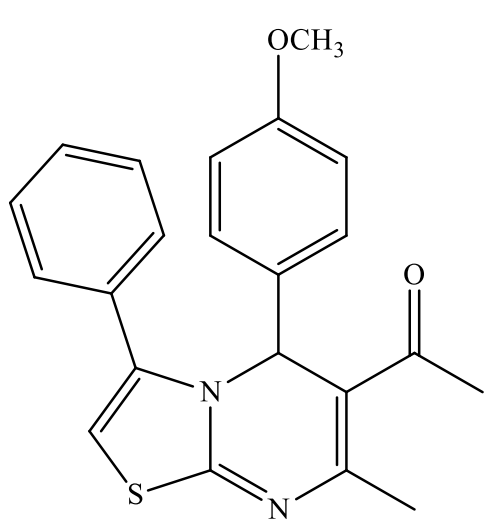

$4 \mathrm{~b}$

IR $\left(\mathrm{KBr}, \mathrm{cm}^{-1}\right): \gamma 2972(-\mathrm{CH}-), 1676(>\mathrm{C}=\mathrm{O}), 1560(-\mathrm{C}=\mathrm{N}-)$ $\mathrm{cm}^{-1} ;{ }^{1} \mathrm{H} \mathrm{NMR}\left(\mathrm{CDCl}_{3}\right): \delta 2.28\left(\mathrm{~s}, 3 \mathrm{H},-\mathrm{COCH}_{3}\right), 2.90(\mathrm{~s}, 3 \mathrm{H}$, $\left.-\mathrm{CH}_{3}\right), 3.85\left(\mathrm{~s}, 3 \mathrm{H},-\mathrm{OCH}_{3}\right), 5.26(\mathrm{~s}, 1 \mathrm{H},-\mathrm{CH}-), 6.85(\mathrm{~s}, 1 \mathrm{H}$, $>\mathrm{C}=\mathrm{CH}-$ ); 6.88-7.70 (m, 9H, Ar-H), ${ }^{13} \mathrm{C}$ NMR (DMSO-d6): $\delta 21.08$ (C-10), $27.05(\mathrm{C}-12), 55.82\left(-\mathrm{OCH}_{3}\right), 62.14(\mathrm{C}-5)$, 108.34 (C-2), 114.26 (C-21 and C-23), 128.25 (C-16), 125.84 (C-20 and C-24), 128.54 (C-14 and C-18), 128.86 (C15 and C-17), 132.24 (C-6), 130.74 (C-13), 135.66 (C-19), 145.14 (C-3), 151.86 (C-7), 158.60 (C-9), 158.62 (C-22), 196.84 (C-11); $\mathrm{MS}$ for $\mathrm{C}_{22} \mathrm{H}_{20} \mathrm{~N}_{2} \mathrm{O}_{2} \mathrm{~S}: 376\left(\mathrm{MH}^{+}, 100 \%\right), 377$ $\left(\mathrm{MH}^{+1}, 24.6 \%\right), 378\left(\mathrm{MH}^{+2}, 4.7 \%\right)$; Elemental Analysis (\%): Calculated: C, 70.19; H, 5.35; N, 7.44; Found: C, 70.18; H, $5.36 ; \mathrm{N}, 7.43$.

1-(5-(4-chlorophenyl)-7-methyl-3-phenyl-5H-thiazolo[3,2- $\alpha]$ pyrimidine-6-yl)ethanone (4c): Obtained from 4-phenylthiazole-2-amine (1a, 1.76g, 10.00mmol), acetylacetone $(2,2.00 \mathrm{~g}$, $20.00 \mathrm{mmol}) 4$-chlorobenzaldehyde $(3 \mathrm{c}, 1.40 \mathrm{~g}, 10.00 \mathrm{mmol})$ and PTSA $(2.50 \mathrm{~g}, 15.00 \mathrm{mmol})$ as yellow solid, yield $80 \%$ (3.05g), m.p. $118-120^{\circ} \mathrm{C}$.

IR $\left(\mathrm{KBr}, \mathrm{cm}^{-1}\right): \gamma 2968(-\mathrm{CH}-), 1679(>\mathrm{C}=\mathrm{O}), 1570(-\mathrm{C}=\mathrm{N}-) \mathrm{cm}^{-}$

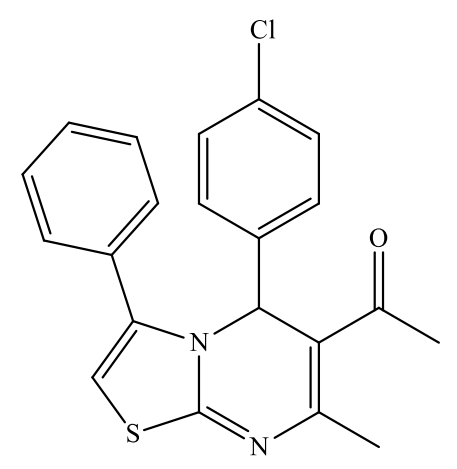

$4 \mathrm{c}$

${ }^{1} ;{ }^{1} \mathrm{H} \mathrm{NMR}\left(\mathrm{CDCl}_{3}\right): \delta 2.27\left(\mathrm{~s}, 3 \mathrm{H},-\mathrm{COCH}_{3}\right), 2.92\left(\mathrm{~s}, 3 \mathrm{H},-\mathrm{CH}_{3}\right)$, $5.24(\mathrm{~s}, 1 \mathrm{H},-\mathrm{CH}-), 6.96(\mathrm{~s}, 1 \mathrm{H},>\mathrm{C}=\mathrm{CH}-)$; 7.30-7.75 (m, 9H, Ar$\mathrm{H}$ ); ${ }^{13} \mathrm{C}$ NMR (DMSO- $d 6$ ): $\delta 21.32$ (C-10), 27.16 (C-12), 62.30 (C-5), 108.55 (C-2), 126.04 (C-20 and C-24), 127.90 (C-16), 128.42 (C-14 and C-18), 128.60 (C-15 and C-17), 128.74 (C-21 and C-23), 130.08 (C-6), 132.26 (C-13), 132.38 (C-22), 141.50 (C-19), 145.14 (C-3), 151.64 (C-7), 158.22 (C-9), 196.46 (C-11); MS for $\mathrm{C}_{21} \mathrm{H}_{17} \mathrm{ClN}_{2} \mathrm{OS}: 380\left(\mathrm{MH}^{+}, 100 \%\right), 382\left(\mathrm{MH}^{+2}, 36.5 \%\right)$, $381\left(\mathrm{MH}^{+1}, 23 \%\right)$; Elemental Analysis (\%): Calculated: C, 66.22; H, 4.50; Cl, 9.31; N, 7.35; Found: C, 66.24; H, 4.48; Cl, 9.30; N, 7.33 .

1-(7-methyl-3-phenyl-5-(p-tolyl)-5H-thiazolo[3,2- $\alpha$ ]pyrimidine-6-yl)ethanone (4d): Obtained from 4-phenylthiazole-2-amine (1a, 1.76g, 10.00mmol), acetylacetone $(2,2.00 \mathrm{~g}, 20.00 \mathrm{mmol})$ 4-methylbenzaldehyde (3d, 1.20g, 10.00mmol) and PTSA $(2.50 \mathrm{~g}, 15.00 \mathrm{mmol})$ as yellow solid, yield $82 \%$ (2.95g), m.p. $132-134^{\circ} \mathrm{C}$.

IR (KBr, cm $\left.{ }^{-1}\right): \gamma 2970(-\mathrm{CH}-), 1669(>\mathrm{C}=\mathrm{O}), 1568(-\mathrm{C}=\mathrm{N}-) \mathrm{cm}^{-1}$;

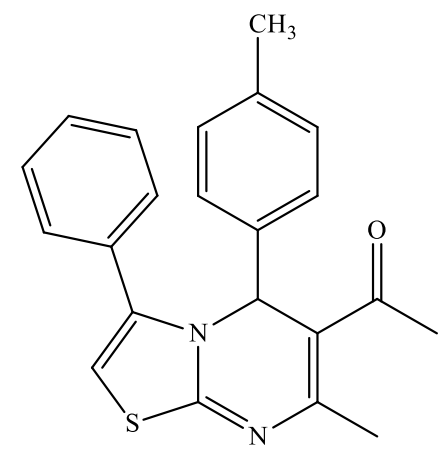

$4 d$

${ }^{1} \mathrm{H}$ NMR $\left(\mathrm{CDCl}_{3}\right): \delta 2.23\left(\mathrm{~s}, 3 \mathrm{H},-\mathrm{COCH}_{3}\right), 2.35\left(\mathrm{~s}, 3 \mathrm{H}, \mathrm{Ar}-\mathrm{CH}_{3}\right)$, $2.94\left(\mathrm{~s}, 3 \mathrm{H},-\mathrm{CH}_{3}\right), 5.22$ (s, 1H, -CH-), 6.98 (s, 1H, >C=CH-), 7.10$7.74(\mathrm{~m}, 9 \mathrm{H}, \mathrm{Ar}-\mathrm{H}) ;{ }^{13} \mathrm{C}$ NMR (DMSO-d6): $\delta 21.04\left(-\mathrm{CH}_{3}\right) 21.44$ (C-10), 27.20 (C-12), 62.24 (C-5), 108.06 (C-2), 126.84 (C-20 and C-24), 127.80 (C-16), 128.32 (C-14 and C-18), 128.66 (C-15 and C-17), 128.72 (C-21 and C-23), 130.60 (C-13), 131.84 (C-6), 136.44 (C-22), 140.32 (C-19), 145.14 (C-3), 151.68 (C-7), 158.22 (C-9), 196.50 (C-11); MS for $\mathrm{C}_{22} \mathrm{H}_{20} \mathrm{~N}_{2} \mathrm{OS}: 360\left(\mathrm{MH}^{+}, 100 \%\right), 361$ $\left(\mathrm{MH}^{+2}, 25.5 \%\right), 362\left(\mathrm{MH}^{+1}, 5.1 \%\right)$; Elemental Analysis (\%): Calculated: C, 73.30; H, 5.59; N, 7.77; Found: C, 73.328; H, 5.60; N, 7.78 . 
1-(3-(4-methoxyphenyl)-7-methyl-5-phenyl-5H-thiazolo[3,2- $\alpha$ ]pyrimidine-6-yl)ethanone (4e): Obtained from 4-(4-methoxyphenyl)thiazole-2-amine (1b, 2.06g, 10.00mmol), acetylacetone $(2,2.00 \mathrm{~g}, 20.00 \mathrm{mmol})$ benzaldehyde $(3 \mathrm{a}, 1.06 \mathrm{~g}, 10.00 \mathrm{mmol})$ and PTSA $(2.50 \mathrm{~g}$, $15.00 \mathrm{mmol})$ as yellow solid, yield $80 \%(3.00 \mathrm{~g})$, m.p. $130-132^{\circ} \mathrm{C}$.

IR (KBr, cm $\left.{ }^{-1}\right): \gamma 2969$ (-CH-), $1674(>\mathrm{C}=\mathrm{O}), 1574(-\mathrm{C}=\mathrm{N}-) \mathrm{cm}^{-1}$;<smiles>COc1ccc(C2=CSC3=NC(C)=C(C(C)=O)C(c4ccccc4)N23)cc1</smiles>

${ }^{1} \mathrm{H}$ NMR $\left(\mathrm{CDCl}_{3}\right): \delta 2.26\left(\mathrm{~s}, 3 \mathrm{H},-\mathrm{COCH}_{3}\right), 2.90\left(\mathrm{~s}, 3 \mathrm{H},-\mathrm{CH}_{3}\right)$, $3.85\left(\mathrm{~s}, 3 \mathrm{H},-\mathrm{OCH}_{3}\right), 5.21(\mathrm{~s}, 1 \mathrm{H},-\mathrm{CH}-), 6.90(\mathrm{~s}, 1 \mathrm{H},>\mathrm{C}=\mathrm{CH}-)$, 6.94-7.60 (m, 9H, Ar-H); ${ }^{13} \mathrm{C}$ NMR (DMSO-d6): $\delta 21.48(\mathrm{C}-10)$, $27.26(\mathrm{C}-12), 55.52\left(-\mathrm{OCH}_{3}\right), 62.08(\mathrm{C}-5), 108.26(\mathrm{C}-2), 121.24$ (C-15 and C-17), 123.46 (C-13), 126.86 (C-22), 127.05 (C-20 and C-24), 128.64 (C-21 and C-23), 129.84 (C-14 and C-18), 132.00 (C-6), 143.23 (C-19), 145.08 (C-3), 151.86 (C-7), 158.44 (C-9), 159.80 (C-16), 196.54 (C-11); (C-7), 160.08 (C-9), 163.06 (C16), MS for $\mathrm{C}_{22} \mathrm{H}_{20} \mathrm{~N}_{2} \mathrm{O}_{2} \mathrm{~S}: 376\left(\mathrm{MH}^{+}, 100 \%\right), 377\left(\mathrm{MH}^{+1}, 24.2 \%\right)$, $378\left(\mathrm{MH}^{+2}, 4.8 \%\right)$; Elemental Analysis (\%): Calculated: C, 70.19; H, 5.35; N, 7.44; Found: C, C, 70.20; H, 5.34; N, 7.42.

1-(3,5-bis(4-methoxyphenyl)-7-methyl-5H-thiazolo[3,2- $\alpha$ ]pyrimidine-6-yl)ethanone (4f): Obtained from 4-(4-methoxyphenyl)thiazole-2-amine (1b, 2.07g, 10.00mmol), acetylacetone $(2,2.00 \mathrm{~g}, 20.00 \mathrm{mmol})$ 4-methoxybenzaldehyde $(3 \mathrm{~b}, 1.36 \mathrm{~g}, 10.00 \mathrm{mmol})$ and PTSA $(2.50 \mathrm{~g}$, $15.00 \mathrm{mmol})$ as yellow solid, yield $86 \%(3.49 \mathrm{~g})$, m.p. $140-142^{\circ} \mathrm{C}$.

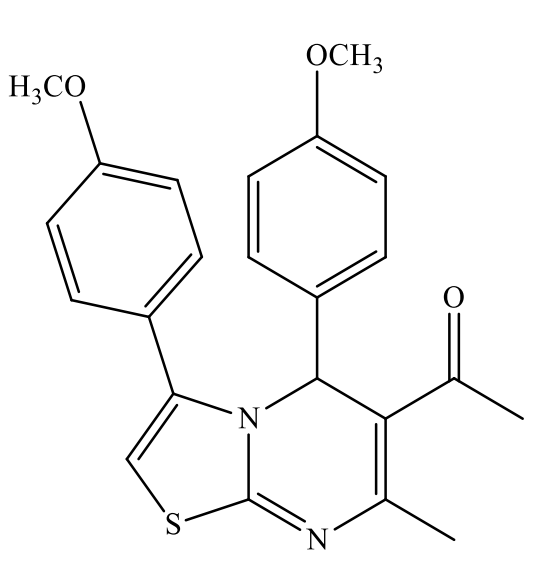

$4 \mathrm{f}$

$\mathrm{IR}\left(\mathrm{KBr}, \mathrm{cm}^{-1}\right): \gamma 2967(-\mathrm{CH}-), 1671(>\mathrm{C}=\mathrm{O}), 1573(-\mathrm{C}=\mathrm{N}-$ ) $\mathrm{cm}^{-1} ;{ }^{1} \mathrm{H} \mathrm{NMR}\left(\mathrm{CDCl}_{3}\right): \delta 2.25\left(\mathrm{~s}, 3 \mathrm{H},-\mathrm{COCH}_{3}\right), 2.96(\mathrm{~s}$, $\left.3 \mathrm{H},-\mathrm{CH}_{3}\right), 3.80-3.85\left(\mathrm{~s}, 6 \mathrm{H},-\mathrm{OCH}_{3}\right), 5.25$ (s, $\left.1 \mathrm{H},-\mathrm{CH}-\right)$, $6.94(\mathrm{~s}, 1 \mathrm{H},>\mathrm{C}=\mathrm{CH}-), 6.96-7.55(\mathrm{~m}, 8 \mathrm{H}, \mathrm{Ar}-\mathrm{H}) ;{ }^{13} \mathrm{C} \mathrm{NMR}$ (DMSO-d6): $\delta 21.40$ (C-10), 27.04 (C-12), 55.82 $\left.\mathrm{OCH}_{3}\right), 56.04\left(-\mathrm{OCH}_{3}\right), 62.06(\mathrm{C}-5), 108.64(\mathrm{C}-2), 114.04$ (C-21 and C-23), 121.28 (C-15 and C-17), 123.06 (C-13), 125.82 (C-20 and C-24), 129.86 (C-14 and C-18), 132.23 (C-6), 135.62 (C-19), 145.28 (C-3), 151.88 (C-7), 158.42 (C-9), 158.87 (C-22), 159.80 (C-16), 196.62 (C-11); MS for $\mathrm{C}_{23} \mathrm{H}_{22} \mathrm{~N}_{2} \mathrm{O}_{3} \mathrm{~S}: 406\left(\mathrm{MH}^{+}, 100 \%\right), 407\left(\mathrm{MH}^{+1}, 25.2 \%\right)$, $408\left(\mathrm{MH}^{+2}, 4.1 \%\right)$; Elemental Analysis (\%): Calculated: C, 67.96; H, 5.46; N, 6.89; Found: C, 67.98; H, 5.44; N, 6.85 .

1-(5-(4-chlorophenyl)-3-(4-methoxyphenyl)-7-methyl-5H-thiazolo[3,2- $\alpha$ ]pyrimidine-6yl)ethanone (4g): Obtained from 4-(4-methoxyphenyl)thiazole-2-amine (1b, $2.06 \mathrm{~g}$, $10.00 \mathrm{mmol})$, acetylacetone $(2,2.00 \mathrm{~g}, 20.00 \mathrm{mmol})$ 4-chlorobenzaldehyde (3c, $1.40 \mathrm{~g}$, $10.00 \mathrm{mmol})$ and PTSA $(2.50 \mathrm{~g}, 15.00 \mathrm{mmol})$ as yellow solid, yield $83 \%$ (3.40g), m.p. 148$150^{\circ} \mathrm{C}$. 


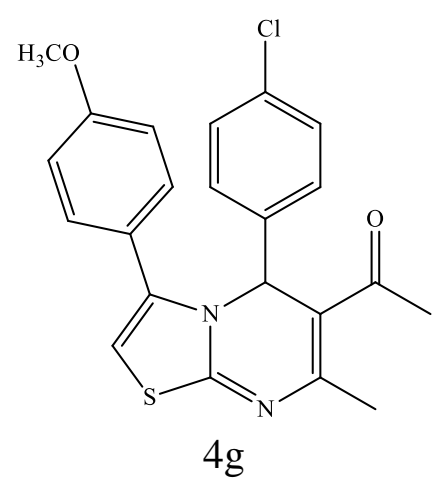

IR $\left(\mathrm{KBr}, \mathrm{cm}^{-1}\right): \gamma 2971(-\mathrm{CH}-), 1672(>\mathrm{C}=\mathrm{O}), 1571(-\mathrm{C}=\mathrm{N}-) \mathrm{cm}^{-}$ 1; ${ }^{1} \mathrm{H}$ NMR $\left(\mathrm{CDCl}_{3}\right): \delta 2.28\left(\mathrm{~s}, 3 \mathrm{H},-\mathrm{COCH}_{3}\right), 2.93\left(\mathrm{~s}, 3 \mathrm{H},-\mathrm{CH}_{3}\right)$, $3.84\left(\mathrm{~s}, 6 \mathrm{H},-\mathrm{OCH}_{3}\right), 5.23$ (s, 1H, -CH-), 6.96 (s, 1H, >C=CH-), 6.98-7.55 (m, 8H, Ar-H); ${ }^{13} \mathrm{C} \mathrm{NMR}$ (DMSO- $\left.d 6\right): \delta 21.42(\mathrm{C}-10)$, 27.06 (C-12), $55.66\left(-\mathrm{OCH}_{3}\right), 62.24(\mathrm{C}-5), 108.26(\mathrm{C}-2) 121.14$ (C-15 and C-17), 123.22 (C-13), 126.24 (C-20 and C-24), 128.76 (C-21 and C-23) 129.84 (C-14 and C-18), 132.04 (C-6) 132.46 (C-22), 141.40 (C-19), 144.88 (C-3), 151.80 (C-7), 158.46 (C-9), 159.90 (C-16), 196.56 (C-11); MS for $\mathrm{C}_{22} \mathrm{H}_{19} \mathrm{ClN}_{2} \mathrm{O}_{2} \mathrm{~S}: 410\left(\mathrm{MH}^{+}, 100 \%\right), 412\left(\mathrm{MH}^{+1}, 36.8 \%\right), 411$ $\left(\mathrm{MH}^{+2}, 24 \%\right)$; Elemental Analysis (\%): Calculated: C, 64.30; H, 4.66; Cl, 8.63; N, 6.82; Found: C, 64.28; H, 4.65; Cl, 8.62; N, 6.84 .

1-(3-(4-methoxyphenyl)-7-methyl-5-( $p$-tolyl)-5H-thiazolo[3,2- $\alpha]$ pyrimidine-6-yl)ethanone (4h): Obtained from 4-(4-methoxyphenyl)thiazole-2-amine (1b, 2.06g, 10.00mmol), acetylacetone $(2,2.00 \mathrm{~g}, 20.00 \mathrm{mmol})$ 4-methylbenzaldehyde $(3 \mathrm{~d}, 1.20 \mathrm{~g}, 10.00 \mathrm{mmol})$ and PTSA $(2.50 \mathrm{~g}, 15.00 \mathrm{mmol})$ as yellow solid, yield $81 \%(3.15 \mathrm{~g})$, m.p. $148-150^{\circ} \mathrm{C}$.

IR $\left(\mathrm{KBr}, \mathrm{cm}^{-1}\right): \gamma 2970(-\mathrm{CH}-), 1675(>\mathrm{C}=\mathrm{O}), 1576(-\mathrm{C}=\mathrm{N}-) \mathrm{cm}^{-}$ 1, ${ }^{1} \mathrm{H}$ NMR $\left(\mathrm{CDCl}_{3}\right): \delta 2.26$ (s, 3H, $\left.-\mathrm{COCH}_{3}\right), 2.34$ (s, 3H, Ar-

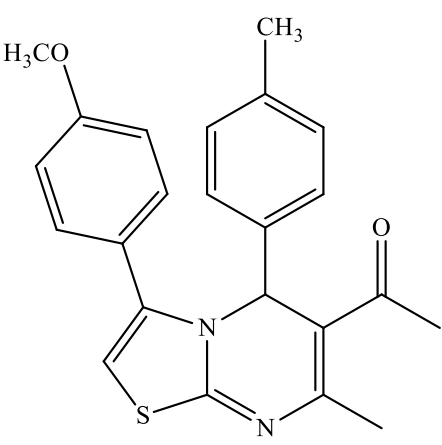

$4 \mathrm{~h}$ $\left.\mathrm{CH}_{3}\right), 2.92\left(\mathrm{~s}, 3 \mathrm{H},-\mathrm{CH}_{3}\right), 3.83\left(\mathrm{~s}, 3 \mathrm{H},-\mathrm{OCH}_{3}\right), 5.20$ (s, $1 \mathrm{H},-\mathrm{CH}-$ ), $6.94(\mathrm{~s}, 1 \mathrm{H},>\mathrm{C}=\mathrm{CH}-), 6.96-7.58(\mathrm{~m}, 8 \mathrm{H}, \mathrm{Ar}-\mathrm{H}) ;{ }^{13} \mathrm{C} \mathrm{NMR}$ (DMSO-d6): $\delta 21.22\left(\mathrm{Ar}^{\left.-\mathrm{CH}_{3}\right)} 21.46(\mathrm{C}-10), 27.22(\mathrm{C}-12)\right.$, $55.94\left(-\mathrm{OCH}_{3}\right), 62.08(\mathrm{C}-5), 108.40(\mathrm{C}-2), 126.90(\mathrm{C}-20$ and $\mathrm{C}-$ 24), 160.02 (C-16), 129.86 (C-14 and C-18), 121.10 (C-15 and C-17), 128.92 (C-21 and C-23), 123.24 (C-13), 132.06 (C-6), 136.40 (C-22), 140.46 (C-19), 144.92 (C-3), 151.52 (C-7), 158.20 (C-9), 196.80 (C-11); $\mathrm{MS}$ for $\mathrm{C}_{23} \mathrm{H}_{22} \mathrm{~N}_{2} \mathrm{O}_{2} \mathrm{~S}: 390\left(\mathrm{MH}^{+}\right.$, $100 \%), 391\left(\mathrm{MH}^{+1}, 26.5 \%\right), 392\left(\mathrm{MH}^{+2}, 5.3 \%\right)$; Elemental Analysis (\%): Calculated: C, 70.74; H, 5.68; N, 7.17; Found: C, 70.72; H, 5.69; N, 7.16.

1-(3-(4-chlorophenyl)-7-methyl-5-phenyl-5H-thiazolo[3,2- $\alpha]$ pyrimidine-6-yl)ethanone (4i): Obtained from 4-(4-chlorophenyl)thiazole-2-amine (1c, $2.10 \mathrm{~g}, 10.00 \mathrm{mmol})$, acetylacetone (2, $2.00 \mathrm{~g}, 20.00 \mathrm{mmol})$ benzaldehyde $(3 \mathrm{a}, 1.06 \mathrm{~g}, 10.00 \mathrm{mmol})$ and PTSA $(2.50 \mathrm{~g}, 15.00 \mathrm{mmol})$ as yellow solid, yield $80 \%$ (3.04), m.p. $144-146^{\circ} \mathrm{C}$.

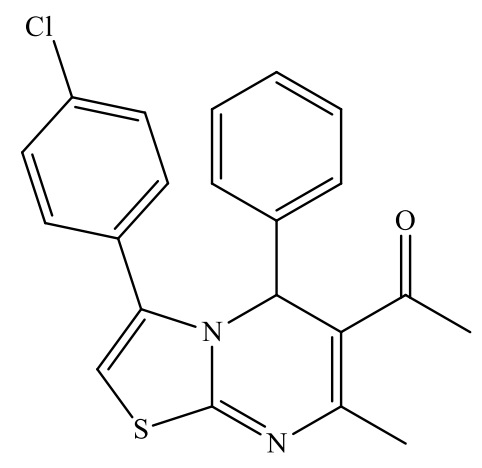

$4 \mathrm{i}$

IR $\left(\mathrm{KBr}, \mathrm{cm}^{-1}\right): \gamma 2972(-\mathrm{CH}-), 1673(>\mathrm{C}=\mathrm{O}), 1577(-\mathrm{C}=\mathrm{N}-) \mathrm{cm}^{-}$ ${ }^{1} ;{ }^{1} \mathrm{H} \mathrm{NMR}\left(\mathrm{CDCl}_{3}\right): \delta 2.28\left(\mathrm{~s}, 3 \mathrm{H},-\mathrm{COCH}_{3}\right), 2.90$ (s, 3H, $\left.\mathrm{CH}_{3}\right), 5.22$ (s, 1H, -CH-), 6.95 (>C=CH-), 7.22-7.45 (m, 9H, Ar$\mathrm{H}) ;{ }^{13} \mathrm{C}$ NMR (DMSO-d6): $\delta 21.30(\mathrm{C}-10), 27.12(\mathrm{C}-12), 62.04$ (C-5), 108.42 (C-2), 120.46 (C-14 and C-18), 126.80 (C-22), 127.06 (C-20 and C-24), 128.64 (C-21 and C-23), 128.66 (C-15 and C-17), 128.82 (C-13), 131.94 (C-6), 133.62 (C-16), 143.32 (C-19), 145.08 (C-3), 151.92 (C-7), 158.20 (C-9), 196.40 (C11); MS for $\mathrm{C}_{21} \mathrm{H}_{17} \mathrm{ClN}_{2} \mathrm{OS}$ : $380\left(\mathrm{MH}^{+}, 100 \%\right), 382\left(\mathrm{MH}^{+1}\right.$, $36.5 \%), 381\left(\mathrm{MH}^{+2}, 22.9 \%\right), 383$ (7.4\%); Elemental Analysis (\%): Calculated: C, 66.22; H, 4.50; Cl, 9.31; N, 17.35; Found: C, 66.20; H, 4.51; Cl, 9.32; N, 17.34. 
1-(3-(4-chlorophenyl)-5-(4-methoxyphenyl)-7-methyl-5H-thiazolo[3,2- $\alpha$ ]pyrimidine-6yl)ethanone (4j): Obtained from 4-(4-chlorophenyl)thiazole-2-amine (1c, 2.10g, 10.00mmol), acetylacetone $(2,2.00 \mathrm{~g}, 20.00 \mathrm{mmol}) 4$-methoxybenzaldehyde $(3 \mathrm{~b}, 1.36 \mathrm{~g}, 10.00 \mathrm{mmol})$ and PTSA $(2.50 \mathrm{~g}, 15.00 \mathrm{mmol})$ as yellow solid, yield $80 \%$ (3.28g), m.p. $150-152^{\circ} \mathrm{C}$.

IR ( $\left.\mathrm{KBr}, \mathrm{cm}^{-1}\right): \gamma 2967$ (-CH-), $1676(>\mathrm{C}=\mathrm{O}), 1572(-\mathrm{C}=\mathrm{N}-) \mathrm{cm}^{-}$<smiles>COc1ccc(C2C(C(C)=O)=C(C)N=C3SC=C(c4ccc(Cl)cc4)N32)cc1</smiles>

$4 \mathrm{j}$

${ }^{1} ;{ }^{1} \mathrm{H} \mathrm{NMR}\left(\mathrm{CDCl}_{3}\right): \delta 2.24$ (s, 3H, $\left.-\mathrm{COCH}_{3}\right), 2.93\left(\mathrm{~s}, 3 \mathrm{H},-\mathrm{CH}_{3}\right)$, $3.83\left(\mathrm{~s}, 3 \mathrm{H},-\mathrm{OCH}_{3}\right), 5.23$ (s, 1H, -CH-), 6.93 (>C=CH-), 6.96$7.48(\mathrm{~m}, 8 \mathrm{H}, \mathrm{Ar}-\mathrm{H}) ;{ }^{13} \mathrm{C}$ NMR (DMSO-d6): $\delta 21.30(\mathrm{C}-10)$, $27.04(\mathrm{C}-12), 55.82\left(-\mathrm{OCH}_{3}\right), 62.24(\mathrm{C}-5), 108.26(\mathrm{C}-2), 114.24$ (C-21 and C-23), 120.34 (C-14 and C-18), 125.70 (C-20 and C24), 128.50 (C-13), 128.82 (C-15 and C-17), 132.04 (C-6), 133.62 (C-16), 135.84 (C-19), 144.84 (C-3), 151.52 (C-7), 158.40 (C-9), 158.66 (C-22), 196.56 (C-11); MS for $\mathrm{C}_{22} \mathrm{H}_{19} \mathrm{ClN}_{2} \mathrm{O}_{2} \mathrm{~S}: 410\left(\mathrm{MH}^{+}, 100 \%\right), 412\left(\mathrm{MH}^{+1}, 36.80 \%\right), 411$ $\left(\mathrm{MH}^{+2}, 24.0 \%\right), 413$ (7.90\%); Elemental Analysis (\%): Calculated: C, 64.30; H, 4.66; Cl, 8.63; N, 6.82; Found: C, $64.28 ; \mathrm{H}, 4.65 ; \mathrm{Cl}, 8.64 ; \mathrm{N}, 6.80$.

1-(3,5-bis(4-chlorophenyl)-7-methyl-5H-thiazolo[3,2- $\alpha]$ pyrimidine-6-yl)ethanone

(4k):

Obtained from 4-(4-chlorophenyl)thiazole-2-amine (1c, $2.10 \mathrm{~g}, 10.00 \mathrm{mmol})$, acetylacetone (2, $2.00 \mathrm{~g}, 20.00 \mathrm{mmol})$ 4-chlorobenzaldehyde (3c, $1.40 \mathrm{~g}, 10.00 \mathrm{mmol})$ and PTSA $(2.50 \mathrm{~g}$, $15.00 \mathrm{mmol})$ as yellow solid, yield $82 \%(3.39 \mathrm{~g})$, m.p. $132-134^{\circ} \mathrm{C}$.

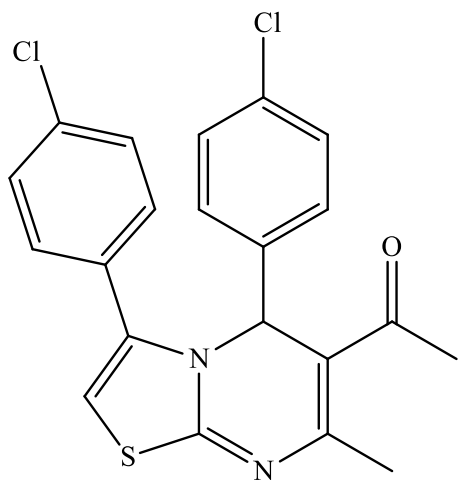

$4 \mathrm{k}$

IR (KBr, cm $\left.{ }^{-1}\right): \gamma 2975(-\mathrm{CH}-), 1671(>\mathrm{C}=\mathrm{O}), 1576(-\mathrm{C}=\mathrm{N}-) \mathrm{cm}^{-}$ ${ }^{1} ;{ }^{1} \mathrm{H} \mathrm{NMR}\left(\mathrm{CDCl}_{3}\right): \delta 2.28\left(\mathrm{~s}, 3 \mathrm{H},-\mathrm{COCH}_{3}\right), 2.91\left(\mathrm{~s}, 3 \mathrm{H},-\mathrm{CH}_{3}\right)$, $5.21(\mathrm{~s}, 1 \mathrm{H},-\mathrm{CH}-), 6.94(\mathrm{~s}, 1 \mathrm{H},>\mathrm{C}=\mathrm{CH}-), 7.30-7.50(\mathrm{~m}, 8 \mathrm{H}, \mathrm{Ar}-$ $\mathrm{H}) ;{ }^{13} \mathrm{C}$ NMR (DMSO-d6): $\delta 21.36$ (C-10), 27.09 (C-12), 62.26 (C-5), 108.28 (C-2), 120.30 (C-14 and C-18), 126.24 (C-20 and C-24), 128.68 (C-21 and C-23), 128.80 (C-15 and C-17), 129.06 (C-13), 132.02 (C-6), 132.22 (C-22), 133.64 (C-16), 141.30 (C19), 144.80 (C-3), 151.72 (C-7), 158.42 (C-9), 196.60 (C-11); MS for $\mathrm{C}_{21} \mathrm{H}_{16} \mathrm{Cl}_{2} \mathrm{~N}_{2} \mathrm{OS}: 414\left(\mathrm{MH}^{+}, 100 \%\right), 416\left(\mathrm{MH}^{+1}, 68.4 \%\right)$, $415\left(\mathrm{MH}^{+2}, 23.7 \%\right), 417$ (15.8\%), 418 (13.0\%); Elemental Analysis (\%): Calculated: C, 60.73; H, 3.88; Cl, 17.07; N, 6.74; Found: C, 60.72; H, 3.86; Cl, 17.09; N, 6.73.

1-(3-(4-chlorophenyl)-7-methyl-5-( $p$-tolyl)-5H-thiazolo[3,2- $\alpha]$ pyrimidine-6-yl)ethanone (41): Obtained from 4-(4-chlorophenyl)thiazole-2-amine (1c, $2.10 \mathrm{~g}, 10.00 \mathrm{mmol})$, acetylacetone (2, $2.00 \mathrm{~g}, 20.00 \mathrm{mmol})$ 4-methylbenzaldehyde $(3 \mathrm{~d}, 1.20 \mathrm{~g}, 10.00 \mathrm{mmol})$ and PTSA $(2.50 \mathrm{~g}$, $15.00 \mathrm{mmol})$ as yellow solid, yield $84 \%(3.30 \mathrm{~g})$, m.p. $130-132^{\circ} \mathrm{C}$. 


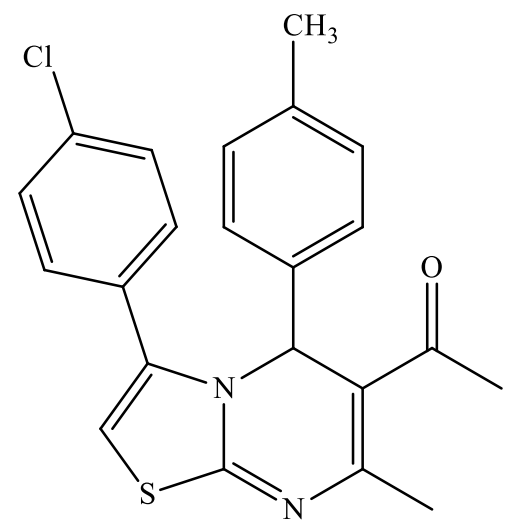

41

IR $\left(\mathrm{KBr}, \mathrm{cm}^{-1}\right): \gamma 2971(-\mathrm{CH}-), 1677(>\mathrm{C}=\mathrm{O}), 1575(-\mathrm{C}=\mathrm{N}-$ ) $\mathrm{cm}^{-1} ;{ }^{1} \mathrm{H} \mathrm{NMR}\left(\mathrm{CDCl}_{3}\right): \delta 2.27\left(\mathrm{~s}, 3 \mathrm{H},-\mathrm{COCH}_{3}\right), 2.34(\mathrm{~s}$, $\left.3 \mathrm{H}, \mathrm{Ar}-\mathrm{CH}_{3}\right), 2.92$ (s, 3H, - $\left.\mathrm{CH}_{3}\right), 5.20$ (s, 1H, -CH-), 6.92 $(\mathrm{s}, 1 \mathrm{H},>\mathrm{C}=\mathrm{CH}-), 7.10-7.45(\mathrm{~m}, 8 \mathrm{H}, \mathrm{Ar}-\mathrm{H}) ;{ }^{13} \mathrm{C} \mathrm{NMR}$ (DMSO-d6): $\delta 21.02\left(\mathrm{Ar}_{-} \mathrm{CH}_{3}\right), 21.24(\mathrm{C}-10), 27.14(\mathrm{C}-$ 12), 62.06 (C-5), 108.40 (C-2), 120.08 (C-14 and C-18), 126.82 (C-20 and C-24), 128.70 (C-15 and C-17), 128.80 (C-13), 128.92 (C-21 and C-23), 131.94 (C-6), 133.46 (C16), 136.56 (C-22), 140.44 (C-19), 145.08 (C-3), 151.60 (C-7), $158.36 \quad$ (C-9), $196.40 \quad(\mathrm{C}-11) ; \quad \mathrm{MS}$ for $\mathrm{C}_{22} \mathrm{H}_{19} \mathrm{ClN}_{2} \mathrm{OS}: 394\left(\mathrm{MH}^{+}, 100 \%\right), 396\left(\mathrm{MH}^{+1}, 37.1 \%\right)$, $395\left(\mathrm{MH}^{+2}, 25.4 \%\right), 397$ (9.1\%); Elemental Analysis (\%): Calculated: C, 66.91; H, 4.85; Cl, 8.98; N, 7.08; Found: C, $66.90 ; \mathrm{H}, 4.83 ; \mathrm{Cl}, 8.99 ; \mathrm{N}, 7.09$.

\subsection{Biological assay.}

2.2.1. Molecular docking studies.

Docking studies of the compounds 4(a-1) were carried out using Autodock-4.2 with the Lamarckian Genetic Algorithm (LGA) computational method to rationalize the plausible bestsuited candidates for binding. Many of the molecules were found to have minimum binding energies ranging from $-7.14 \mathrm{~kJ} / \mathrm{mol}$ to $-8.81 \mathrm{~kJ} / \mathrm{mol}$ against protein DNA gyrase (PDB Code: $1 \mathrm{KZN}$ ) target. Almost all the ligands showed considerable hydrogen bond interaction with active site amino acid residues. The docking study results showed a molecule that has good inhibition constant, vdW + Hbond + desolv energy with the best RMSD value against proteins targets. The details of docked score results are given in Table 1.

\subsubsection{Antimicrobial activity.}

The synthesized compounds 1-(7-methyl-3,5-diphenyl-5H-thiazolo(3,2- $\alpha$ )pyrimidine6-yl)ethanone 4(a-l) were screened for in vitro antibacterial activity against Bacillus cereus (MTCC 8372), Staphylococcus aureus (MTCC 96) [gram positive bacteria] Escherichia coli (MTCC 724) and Klebsiella pneumonia (MTCC 432) [gram negative bacteria] using agar disc diffusion [28] method using Tetracycline used as standard drug. The compounds 4(a-l) were dissolved in DMF (dimethylformamide) at 50 and $100 \mu \mathrm{g} / \mathrm{mL}$ concentration and placed on the inoculated plates after allowing at $4{ }^{\circ} \mathrm{C}$ for $2 \mathrm{~h}$, they were incubated at $37^{\circ} \mathrm{C}$ for 24 hours, and the inhibition zone was measured in millimeters. Besides, in vitro antifungal screening [29] of the compounds 4(a-1) was carried out against Aspergillus flavus (MTCC873), Aspergillus niger (MTCC 281), Fusarium oxysporum (MTCC 284), and Fusarium moniliform (MTCC 156) using Nystatin as standard drug. The microdilution method was used to appraise the minimum inhibitory concentration (MIC) of all the obtained compounds, as summarized in Table 2. The compounds were stable in the Nutrient agar and Potato dextrose agar. The MIC for fungal strains was executed using a 96-well plate. The fungi were preserved on potato dextrose agar (PDA) medium at $28^{\circ} \mathrm{C}$. Six replicate determinations were performed for all the compounds, and results were taken as a mean of at least three determinations. 


\section{Results and Discussion}

The one-pot three-component synthesis of 1-(7-methyl-3,5-diphenyl-5H-thiazolo(3,2a)pyrimidine-6-yl)ethanone 4(a-1) in good yield was achieved initially by Knoevenagel condensation reaction between active methylene acetylacetone (2) with substituted aromatic aldehydes (3a-d) using acidic PTSA [30] in the presence of acetonitrile as solvent. Meanwhile, the addition of 4-phenylthiazole-2-amine (1a-c) to the reaction mixture and refluxed for about 2-3 hours to get the target product $5 H$-thiazolo(3,2- $\alpha)$ pyrimidine-6-yl)ethanone derivatives 4(a-1) (Scheme 1).

The synthesized compounds were characterized by their IR, ${ }^{1} \mathrm{H}$ NMR, ${ }^{13} \mathrm{C}$ NMR, Mass, and elemental analysis. In the IR spectra, 4(a-1) showed the stretching vibration bands at around $2967-2975 \mathrm{~cm}^{-1}$ corresponding to the presence of $-\mathrm{CH}$ - group, vibration bands $1560-1577 \mathrm{~cm}^{-}$ ${ }^{1}$ for $-\mathrm{C}=\mathrm{N}$ - group and vibration band $1669-1679 \mathrm{~cm}^{-1}$ indicates the presence of $>\mathrm{C}=\mathrm{O}$ group in the compound. The ${ }^{1} \mathrm{H}$ NMR spectra of compounds 4(a-1) showed the signals due to $-\mathrm{CH}_{3}$ proton in the region $\delta 2.90$ to $2.96 \mathrm{ppm}$, singlet peaks of $-\mathrm{CO}-\mathrm{CH}_{3}$ group appeared in the region $\delta 2.23$ to $2.28 \mathrm{ppm}$, while singlet peak of $-\mathrm{CH}$ - group appeared in the region $\delta 5.20$ to 2.26 ppm and all other aromatic protons at $\delta 6.88$ to $7.75 \mathrm{ppm}$. The absence of $-\mathrm{NH}_{2}$ singlet peak in the region $\delta 8.80$ to $9.20 \mathrm{ppm}$ confirms the formation of condensation product $4(\mathrm{a}-\mathrm{l})$. In ${ }^{13} \mathrm{C}$ NMR spectra presence of additional peaks in the range of $\delta 21.08$ to $21.48 \mathrm{ppm}(\mathrm{C}-10), \delta 27.04$ to $27.26 \mathrm{ppm}(\mathrm{C}-12)$, and $\delta 62.06$ to $65.20 \mathrm{ppm}(\mathrm{C}-5)$ was observed. All synthesized compounds $4(\mathrm{a}-\mathrm{l})$ showed $\mathrm{MH}^{+}$as a base peak in the mass spectra.

\subsection{Structure-activity relationship.}

Docking studies of compounds 4(a-1) with docked score results were portrayed in Table 1. The compounds $4 \mathrm{k}, 41,4 \mathrm{j}$, and $4 \mathrm{c}$ were found to have minimum binding energy with -8.81 , $-8.47,-8.19$, and $-8.06 \mathrm{~kJ} \mathrm{~mol}^{-1}$, respectively, with one hydrogen bond as shown in figure 1 . Additionally, $4 \mathrm{~b}$ and $4 \mathrm{~d}$ possess comparable binding energy with -8.28 and $-8.22 \mathrm{~kJ} \mathrm{~mol}^{-1}$, respectively, without hydrogen bond. All other compounds were found to have moderate binding energy. The compound $4 \mathrm{k}, 4 \mathrm{l}, 4 \mathrm{j}$, and $4 \mathrm{c}$ found to have the highest ligand efficiency with $-0.33,-0.31,-0.29$, and -0.31 respectively and all other compounds found to have moderate ligand efficiency.

\subsection{Antimicrobial assay.}

The series of synthesized compounds 4(a-1) contains one of the nucleoside base pyrimidine moiety, and we expected good antimicrobial activity, as shown in Table 2 . The binding energy based on the docking study and antimicrobial evaluations is comparable, as shown in table 1 and table 2 . The results revealed that the compounds $4 \mathrm{k}$ showed excellent antibacterial effect with binding energy $-8.81 \mathrm{~kJ} \mathrm{~mol}^{-1}$ against all the tested strains; this may be due to the presence of $-\mathrm{Cl}$ group on both para position of the phenyl rings of thiazole as well as pyrimidine moieties, $4 \mathrm{l}, 4 \mathrm{~b}, 4 \mathrm{~d}$, and $4 \mathrm{j}$ and found to moderate with binding energy -8.47 , $8.28,-8.22$ and $-8.19 \mathrm{~kJ} \mathrm{~mol}^{-1}$ respectively, it may be due to the presence of electron-donating group on one of the phenyl ring of the pyrimidine ring. The compounds $4 \mathrm{i}$ was less active against bacterial strains, but it possesses good antifungal activity with $-7.25 \mathrm{~kJ} \mathrm{~mol}^{-1}$ binding energy; it may be the presence of $-\mathrm{Cl}$ group at the para position of the phenyl ring of thiazole, while $4 \mathrm{c}, 4 \mathrm{j}$ to 41 compounds showed excellent antifungal activity and the remaining 
compounds showed moderate antifungal activity with, it may be due to the presence of an electron-withdrawing group at thiazole or pyrimidine moiety.
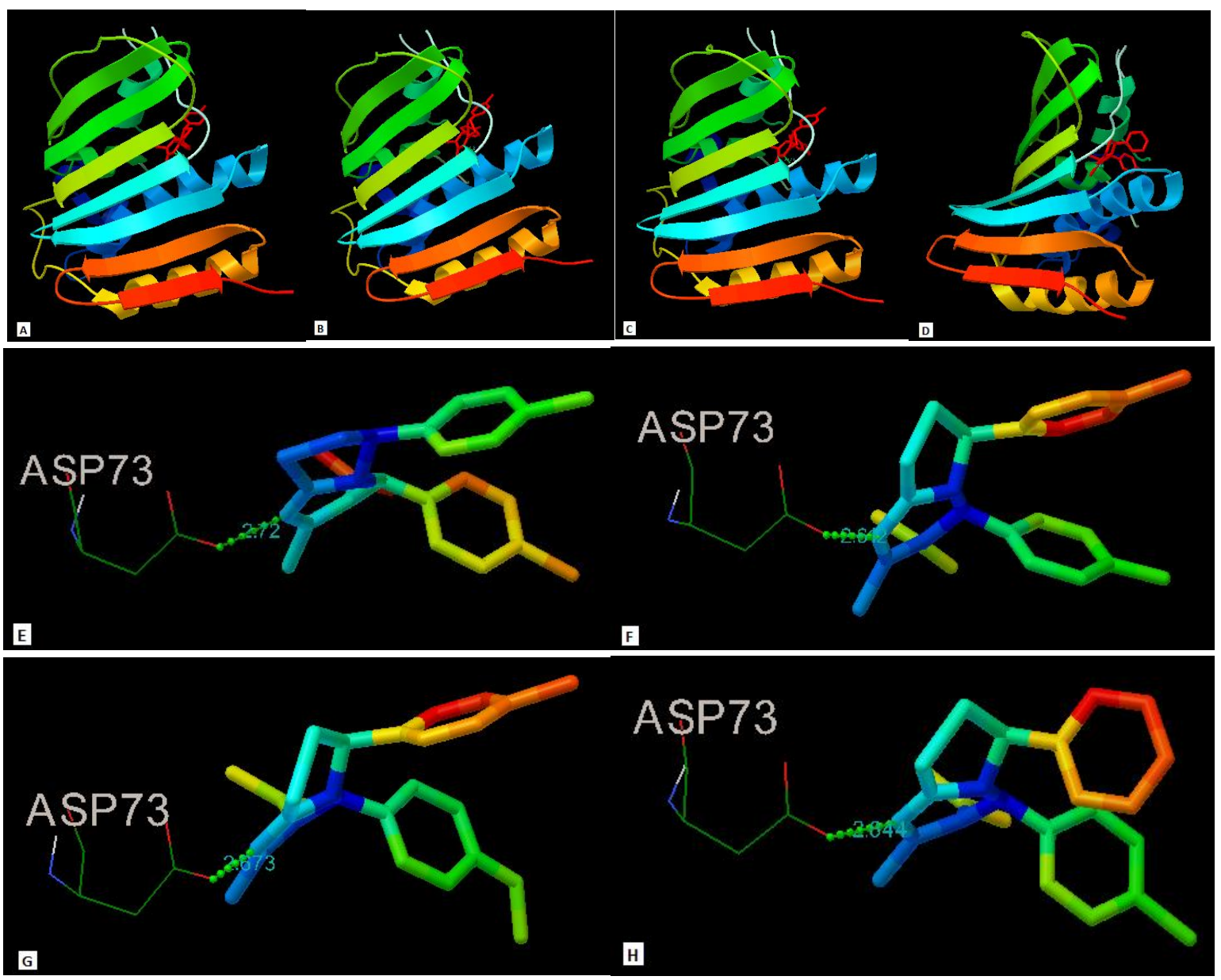

Figure 1. Molecular Docking of (A) 4k, (B) 4l, (C) 4j, (D) 4c against protein target DNA gyrase, and (E) 4k, (F) $4 \mathrm{l},(\mathrm{G}) 4 \mathrm{j},(\mathrm{H}) 4 \mathrm{c}$ showing hydrogen bonding.

Table 1. The docking results of the different ligand molecules (4a-l) with protein target DNA gyrase.

\begin{tabular}{|c|c|c|c|c|c|c|c|}
\hline Compounds & $\begin{array}{c}\text { Binding } \\
\text { Energy } \\
\left(\mathrm{kJ} \mathrm{mol}^{-1}\right)\end{array}$ & $\begin{array}{l}\text { Ligand } \\
\text { Efficiency }\end{array}$ & $\begin{array}{l}\text { Inhibition } \\
\text { Constant }\end{array}$ & $\begin{array}{c}\text { vdW+H- } \\
\text { bond+desolv } \\
\text { energy }\end{array}$ & $\begin{array}{c}\text { No. of } \\
\text { H- } \\
\text { bonds }\end{array}$ & Bonding residues & $\begin{array}{l}\text { Bond } \\
\text { Length } \\
(\AA)\end{array}$ \\
\hline $\mathbf{4 a}$ & -7.97 & -0.32 & 1.43 & -8.85 & 1 & 1KZN:A:ASP73:OD1 & 2.775 \\
\hline $4 \mathrm{~b}$ & -8.28 & -0.31 & 855.01 & -9.47 & - & - & - \\
\hline $4 c$ & -8.06 & -0.31 & 1.24 & -8.93 & 1 & 1KZN:A:ASP73:OD1 & 2.844 \\
\hline 4d & -8.22 & -0.32 & 948.34 & -9.17 & - & - & - \\
\hline $4 e$ & -7.88 & -0.29 & 1.68 & -8.98 & 1 & 1KZN:A:ASP73:OD1 & 2.732 \\
\hline $4 f$ & -7.14 & -0.25 & 5.87 & -8.57 & - & - & - \\
\hline $4 g$ & -7.91 & -0.27 & 1.58 & -9.35 & 1 & 1KZN:A:ASP73:OD1 & 2.803 \\
\hline $4 h$ & -7.89 & -0.28 & 1.65 & -9.05 & - & - & - \\
\hline $4 \mathbf{i}$ & -7.25 & -0.28 & 4.85 & -8.11 & 1 & 1KZN:A:ASN46: HD21 & 1.764 \\
\hline $4 \mathbf{j}$ & -8.19 & -0.29 & 995.56 & -9.31 & 1 & 1KZN:A:ASP73:OD1 & 2.673 \\
\hline $4 \mathbf{k}$ & -8.81 & -0.33 & 348.14 & -9.68 & 1 & 1KZN:A:ASP73:OD1 & 2.720 \\
\hline 41 & -8.47 & -0.31 & 619.68 & -9.34 & 1 & 1KZN:A:ASP73:OD1 & 2.612 \\
\hline
\end{tabular}


Table 2. The minimal inhibitory concentration (MIC), minimal bactericidal concentration (MBC), and minimal fungicidal concentration (MFC) in $\mu \mathrm{g} / \mathrm{mL}$ of synthesized compounds against tested strains.

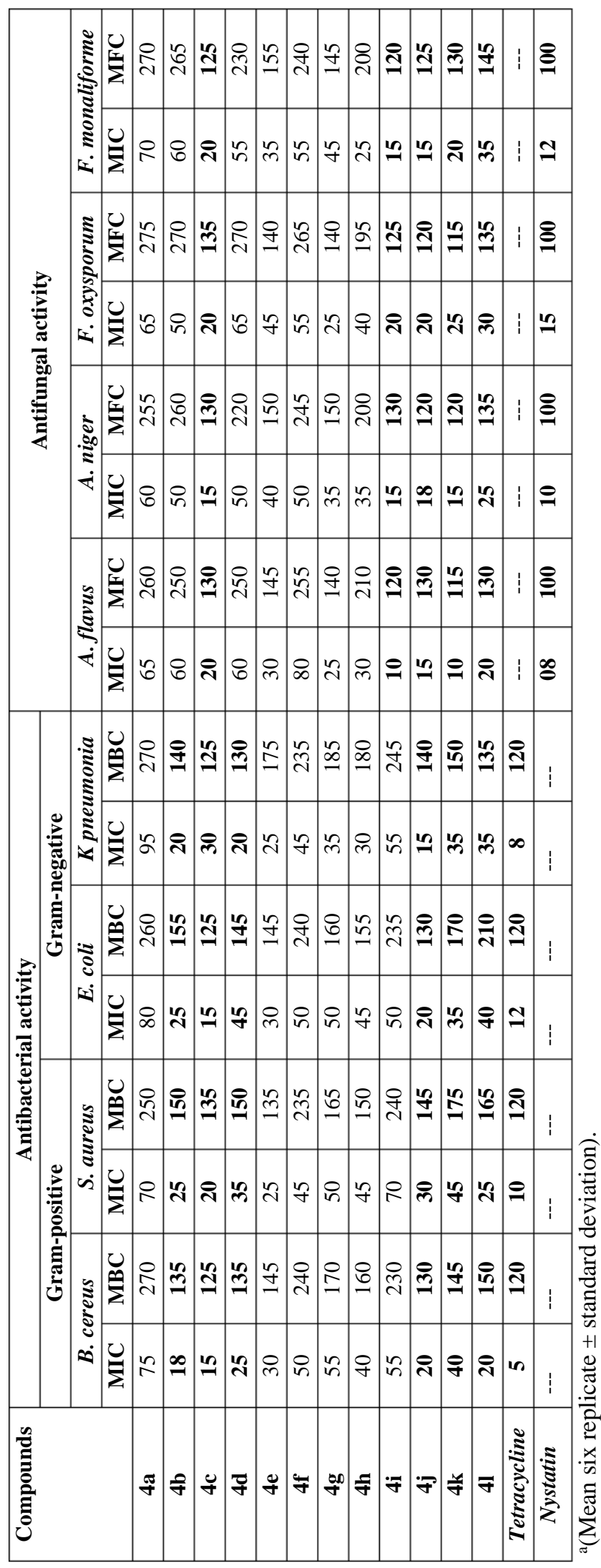

\section{Conclusions}

In conclusion, we have synthesized the bicyclic thiazolo[3,2- $\alpha$ pyrimidine 4(a-1) via a one-pot three-component chemical transformation of derivatives using electron-rich substituent on the phenyl ring of the thiazole and pyrimidine. This method delivers a 
remarkable yield (80-86\%) of the target products in 2-3 hours with low-cost PTSA. All the synthesized compounds have been investigated for their docking study and in vitro antimicrobial activity. Among the synthesized compounds, 4k emerged as an excellent antibacterial agent with the least binding energy against protein DNA gyrase (PDB Code: $1 \mathrm{KZN})$. Also, the compounds $4 \mathrm{k}$ and 41 possess good antifungal activity compared with standard drugs. Hence, $4 \mathrm{k}$ could be a promising drug candidate for microbial infections.

\section{Funding}

This research received no external funding.

\section{Acknowledgments}

Authors (KBU) thank the Principal, Yuvaraja's College, UOM, Mysuru, and Dr. Shridevi is grateful to the CSIR-National Institute for Interdisciplinary Science and Technology (NIIST), Thiruvananthapuram for providing the necessary facility to carry out the research work.

\section{Conflicts of Interest}

The authors declare no conflict of interest.

\section{References}

1. Amit, K.K.; Ashok, K.S.; Sudipta, S.; Bridgehead, N. Thiazolo[3,2-a]pyrimidine: A Privileged Structural Framework in Drug Discovery. Mini. Rev. Med. Chem. 2017, 17, 1488-1499, https://doi.org/10.2174/1389557517666170216142113.

2. Nagaraju, K.; Lalitha, G.; Surya, N.M.; Sandeep, V.H.S.; Bhaskaruni.; Suresh, M.; Sreekantha, B.J. Green synthesis and characterisation of novel [1,3,4]thiadiazolo/benzo[4,5]thiazolo[3,2-a]pyrimidines via multicomponent reaction using vanadium oxide loaded on fluorapatite as a robust and sustainable catalyst. RSC Adv. 2020, 10, 19803-19810, https://doi.org/10.1039/D0RA02298E.

3. Gulhan, T.Z.; Mehlika, D.A.; Zafer, A.K.; Ahmet, O.; Fatih, D.; Sinem, I.; Ozlem, Atl.; Gamze, G. Synthesis and Evaluation of Thiazole - Pyrimidine Derivatives as New Anticandidal and Cytotoxic Agents. Pharm. Chem. J. 2014, 48, 452-455, https://doi.org/10.1007/s11094-014-1130-7.

4. Kaskevich K.I.; Anastasia, A.B; Vladislav, V.G; Dmitrij, M.E; Nataly, I.S.; Albina, V.D. Synthesis of 3 (2)phosphonylated thiazolo [3,2-a] oxopyrimidines. Beilstein J. Org. Chem. 2020, 16, 1947-1954, https://doi.org/10.3762/bjoc.16.161.

5. Viveka, S.; Dinesha; Laxmeshwar, S.S.; Nagaraja, G.K. Ethyl 7-methyl-5-(4-methylphenyl)-3-oxo-2-\{[3(3,4-dichlorophenyl)-1-phe-nyl-1H-pyrazol-4-yl]methylidene $\}-2,3$-dihydro-5H-[1,3]thiazolo[3,2a]pyrimidine-6-carboxylate. Molbank. 2012, 3, 1-5, https://doi.org/10.3390/M776.

6. Mohamed, S. Synthesis of Some Novel Thiazolo[3,2-a]pyrimidine and Pyrimido[2,1-b][1,3]thiazine Derivatives and their Antimicrobial Evaluation. J. Heterocycl. Chem. 2018, 55, 1391-1397, https://doi.org/10.1002/jhet.3174.

7. Nagaraju, K.; Lalitha, G.; Surya, N.M.; Sandeep, V.H.S.; Bhaskaruni.; Suresh, M.; Sreekantha, B.J. Green synthesis and characterisation of novel [1,3,4]thiadiazolo/benzo[4,5]thiazolo[3,2-a]pyrimidines via multicomponent reaction using vanadium oxide loaded on fluorapatite as a robust and sustainable catalyst. RSC Adv. 2020, 10, 19803-19810, https://doi.org/10.1039/D0RA02298E.

8. Ayman, M.S.Y.; Ahmed, M.F.; Rasha, M.F. Microwave assisted synthesis of some new thiazolopyrimidine and pyrimidothiazolopyrimidopyrimidine derivatives with potential antimicrobial activity. Chem. Cent. J. 2018, 12, https://doi.org/10.1186/s13065-018-0419-0.

9. Ravendra, B.K.; Rao, V.K.; Nanda, K.Y.; Polireddy, K.; Venkata, S.K.; Bhaskar, M.; Lokanatha, V.; Naga Raju, C. Identification of substituted [3,2-a] pyrimidines as selective antiviral agents: molecular modeling study. Antivir. Res. 2012, 95, 118-127, https://doi.org/10.1016/j.antiviral.2012.05.010.

10. Thuraka, S.; Pinnu, T.; Annavarapu, V.; Thathapudi, D.; Kotha, P.; Sri Bhashyam, S. One-pot synthesis of thiazolo[3,2-a]pyrimidine derivatives, their cytotoxic evaluation and molecular docking studies. Spectrochim. Acta. A. 2020, 231, https://doi.org/10.1016/j.saa.2020.118056.

11. Wu, F.Y.; Luo, Y.; Hu, C.B. Recent progress in the synthesis of thiazolo[3,2-a]pyrimidine compounds. IOP Conf. Ser. Mater. Sci. Eng. 2018, 292, https://doi.org/10.1088/1757-899X/292/1/012038. 
12. Aggarwal, R.; Garima, S. An insight on medicinal attributes of 1, 2, 4-triazoles. Eur. J. Med. Chem. 2020, 112652, https://doi.org/10.1016/j.ejmech.2020.112652.

13. Youssef, M.M.; Amin, M.A. Microwave assisted synthesis of some new thiazolopyrimidine, thiazolodipyrimidine and thiazolopyrimidothiazolopyrimidine derivatives with potential antioxi-dant and antimicrobial activity. Molecules 2012, 17, 9652-9667, https://dx.doi.org/10.3390\%2Fmolecules17089652.

14. Dinakaran, V.S.; Bomma, B.; Srinivasan, K.K. Fused pyrim-idines: the heterocycle of diverse biological and pharmacological significance. Der. Pharm. Chem. 2012, 4, 255-265.

15. Elena, G.H.; Rubén, A.; Mercedes, G.; José, M.; Ángeles, M.S.; Concepción, P.M. Dihydropyrimidine-2thiones as Eg5 inhibitors and L-type calcium channel blockers: potential antitumour dual agents. Med. Chem. Comm., 2019, 10, 1589-1598, https://doi.org/10.1039/C9MD00108E.

16. Cui Yingna; Changping Li; Ming Bao. Deep eutectic solvents (DESs) as powerful and recyclable catalysts and solvents for the synthesis of 3, 4-dihydropyrimidin-2(1H)-ones/thiones. Green Processing and Synthesis 8, 2019, 1, 568-576, https://doi.org/10.1515/gps-2019-0026.

17. Moty, S.G.A.; Mostafa, A.H.; Salah, A.A.A.; Mahrous, A.A.S. Design and synthesis of some substituted thiazolo [3,2-a] pyrimidine derivatives of potential biological activities. Saudi Pharm J, 2016, 2, 119-132, https://doi.org/10.1016/j.jsps.2013.12.016.

18. Hassan, G.S.; Shahenda, M. El-M.; Ahmad, A. Synthesis and anticancer activity of new thiazolo [3,2-a] pyrimidines: DNA binding and molecular modeling study. Bioorg Chem, 2017, 41-52, https://doi.org/10.1016/j.bioorg.2017.07.008.

19. Huseynzada, A.E.; Jelsch. C.; Akhundzada, H.N.; Soudani, S.; Ben, N.C.; Doria, F.; Hasanova, U. A.; Freccero, M. Synthesis, crystal structure and antibacterial properties of 6-methyl-2-oxo-4-(quinolin-2-yl)-1, 2, 3, 4-tetrahydropyrimidine-5-carboxylate. J. $\quad$ Mol. $\quad$ Struct., 2020, https://doi.org/10.1016/j.molstruc.2020.128581.

20. Khandelwal, S.; Yogesh, K. T.; Esha, R.; Mahendra, K. Green Approaches in Medicinal Chemistry for Sustainable Drug Design, 2020, 245.

21. Wichmann, J.; Adam, G.; Kolczewski, S.; Mutel, V.; Woltering, T. Structure-activity relationships of substituted 5H-thiazolo[3,2-a]pyrimidines as group 2 metabotropic glutamate receptor antagonists. Bioorg. Med. Chem. Lett. 1999, 9, 1573-1576, https://doi.org/10.1016/S0960-894X(99)00227-9.

22. Hussein, M.A.; Abdel Moty, S.G.; Abdel Aziz, S.A.; Abou-Salim, M.A. Synthesis and antimicrobial activity of new substituted dihydropyrimidine derivatives. Bull. Pharm. Sci., Assiut. Univ. 2011, 34, 37-58.

23. Renata, S.; Marcin, W.; Aleksandra, K.W.; Renata, K. A facile synthesis of the novel thiazolo[3,2a]pyrimidine derivatives. Tetrahedron Lett. 2014, 55, 1384-1386, https://doi.org/10.1016/j.tetlet.2014.01.033.

24. Amit, K.K.; Ashok, K.S.; Vinit, R.; Amit, R.; Prakruti, T.; Balaram, G.; Umesh, K.; Atul, R.; Dinesh, K.; Sudipta, S. $p$-TSA-promoted syntheses of $5 H$-benzo[h]thiazolo[2,3- $\beta$ ]quinazoline and indeno[1,2d]thiazolo[3,2- $\alpha$ pyrimidine analogs: molecular modelling and in vitro antitumor activity against hepatocellular carcinoma. Drug. Des. Devel. Ther. 2017, 11, 1623-1642, https://doi.org/10.2147/dddt.s136692.

25. Asieh, K.; Sakineh, A.; Maryam, P. Diastereoselective Sonochemical Synthesis of Spirocyclopropaneoxindoles and Evaluation of Their Antioxidant and Cytotoxic Activities. Chem. Biodivers. 2019, 16, https://doi.org/10.1002/cbdv.201900087.

26. Janardhan, B.; Manjulatha, K.; Srinivas, B.; Rajitha, B.; Muralikrishna, N.; Sadanandam, A. Synthesis, characterization and biological evaluation of fused thiazolo[3,2-a]pyrimidine derivatives. $R S C A d v .2014,4$, 22866-22874, https://doi.org/10.1039/C4RA02514H.

27. Zhang, Z.-H.; Wu, H.-M.; Deng, S.-N.; Cai, X.-Y.; Yao, Y.; Mwenda, M.C.; Wang, J.-Y.; Cai, D.; Chen, Y. Design, Synthesis, and Anticancer Activities of Novel 2-Amino-4-phenylthiazole Scaffold Containing Amide Moieties. J. Chem. 2018, 1-8, https://doi.org/10.1155/2018/4301910.

28. Rosy, R.; Russell, H.; Laura, W. Survey, laboratory and statistical methods for the BSAC Resistance Surveillance Programmes. J. Antimicrob. 2008, 62, 15-28, https://doi.org/10.1093/jac/dkn349.

29. Zgoda, J.R.; Porter, J.R. A convenient micro-dilution method for screening natural products against bacteria and fungi. Pharm. Bio. 2001, 39, 221-225, https://doi.org/10.1076/phbi.39.3.221.5934.

30. Jin, T.; Zhang, S.; Li, T. p-toluenesulfonic acid catalysed efficient synthesis of dihydropyrimidines: improved high yielding protocol for the biginelli reaction. Synthe. Commun. 2002, 32, 1847-1851, https://doi.org/10.1081/SCC-120004068. 